\title{
Impact of Doppler Radar Wind Observations on Australian High-Resolution Numerical Weather Prediction
}

\author{
Susan Rennie, Lawrence Rikus, Nathan Eizenberg, Peter Steinle, and Monika Krysta \\ Science to Services, Australian Bureau of Meteorology, Melbourne, Victoria, Australia
}

(Manuscript received 13 May 2019, in final form 5 December 2019)

\begin{abstract}
The impact of Doppler radar wind observations on forecasts from a developmental, high-resolution numerical weather prediction (NWP) system is assessed. The new 1.5-km limited-area model will be Australia's first such operational NWP system to include data assimilation. During development, the assimilation of radar wind observations was trialed over a 2-month period to approve the initial inclusion of these observations. Three trials were run: the first with no radar data, the second with radial wind observations from precipitation echoes, and the third with radial winds from both precipitation and insect echoes. The forecasts were verified against surface observations from automatic weather stations, against rainfall accumulations using fractions skill scores, and against satellite cloud observations. These methods encompassed verification across a range of vertical levels. Additionally, a case study was examined more closely. Overall results showed little statistical difference in skill between the trials, and the net impact was neutral. While the new observations clearly affected the forecast, the objective and subjective analyses showed a neutral impact on the forecast overall. As a first step, this result is satisfactory for the operational implementation. In future, upgrades to the radar network will start to reduce the observation error, and further improvements to the data assimilation are planned, which may be expected to improve the impact.
\end{abstract}

\section{Introduction}

The Australian Bureau of Meteorology (BoM) is developing its first generation of convection-allowing NWP systems with data assimilation (DA), to replace the current operational downscaling system (Bureau National Operations Centre 2018). This is the first such NWP system at BoM able to make use of the high spatial and temporal resolution observations from Doppler weather radar. BoM follows the efforts of various research and operational organizations to develop and implement Doppler radar assimilation (e.g., Rihan et al. 2008; Simonin et al. 2014; Montmerle and Faccani 2009; Lindskog et al. 2004; Salonen et al. 2011; Xiao et al. 2008; Crook and Sun 2002; Xue et al. 2003).

Many studies have shown a positive impact of assimilating radial wind observations (de Haan 2013; Montmerle and Faccani 2009; Lindskog et al. 2004; Salonen et al. 2011; Xiao et al. 2008; Simonin et al. 2014) by examining case studies (Aksoy et al. 2009; Chung et al. 2009; Choi et al. 2013; Simonin et al. 2014;

Corresponding author: Susan Rennie, susan.rennie@bom.gov.au
Rennie et al. 2011; Zhao et al. 2008) and in more extended trials (Crook and Sun 2002; de Haan 2013; Montmerle and Faccani 2009; Lindskog et al. 2004). Some of these studies also assimilate moisture information from radar or satellite, which provides additional benefit to precipitation forecasts. The impact is typically greatest in the first few hours, but can be neutral after a longer period (Montmerle and Faccani 2009; de Haan 2013).

Although there are many data assimilation methods, most of the aforementioned studies used a form of variational assimilation, typically 3D-Var. The 3D-Var assimilation has been used with HIRLAM (Lindskog et al. 2000), AROME (France) (Montmerle and Faccani 2009), the Met Office Unified Model (UM) (Simonin et al. 2014), and the WRF Model (Korea Meteorological Agency and the United States) (Xiao et al. 2008; Sun and Wang 2013; Sugimoto et al. 2009). The 3D-Var assimilation can be useful for numerical nowcasting as rapid updates are relatively fast and cheap. This is especially important as many radar wind assimilation studies target rapidly evolving storms with the first few hours. However, as computing power increases, more centers are shifting to 4D-Var (Xiao et al. 2008; 
Kawabata et al. 2011; Ballard et al. 2016; Wang et al. 2013), which can favor a longer assimilation window to make use of the temporal evolution of observations.

The BoM partners with the Met Office to use the UM and associated variational analysis system for assimilation; therefore, BoM NWP development follows the Met Office. Initial high-resolution NWP tests have been made with 3D-Var but as the Met Office moves to 4DVar in its operational high-resolution system, the BoM is starting to test its own hourly 4D-Var NWP system. This system is expected to provide forecast products to $36 \mathrm{~h}$ with a latency of up to $2 \mathrm{~h}$ and will not initially be used for rapid updates and nowcasting. It will serve a wide variety of requirements, providing forecasts and warnings that users can act on at a higher temporal and spatial scale than is provided by global NWP.

The development of Doppler radar observation assimilation at the BoM began in 2010. Early effort was devoted to creating and improving automated quality control (QC), which is indispensable for data assimilation. The production of a naïve Bayes classification (Rennie et al. 2015) combined with custom filtering allowed for a respectable discrimination of precipitation echoes and clear air (insect) echoes from various types of clutter. However, effective radar QC is difficult to achieve with single-polarization radars (Rennie et al. 2015) and it was seen during 10 weeks of assimilation in the Sydney 2014 Forecast Demonstration Project (FDP) that clutter bias was affecting some radar scans (Rennie et al. 2018). Conversion of the Australian radar network to dual polarization is at an early stage, and therefore it is anticipated that single-polarization $\mathrm{QC}$ will still be used for most radars when the NWP system with radar assimilation becomes operational.

The FDP also revealed that the benefit of assimilation was dampened by the background error covariances which showed in the analysis increments that observation information was spread across unrealistically large areas (unpublished data). New covariances are being utilized in this study (new transform order as per Wlasak and Cullen 2014), as described in section 2. Thus, this study is the first to quantitatively estimate the impact of assimilating Australia's Doppler radial winds processed with the new single-polarization QC system, and includes the benefits of 4D-Var and new covariances, building on the efforts of Rennie et al. (2015) and Rennie et al. (2018).

One other focus of BoM radar winds is the use of clear air (insect) echoes. Insects can be considered as a data source for wind observations (Wilson et al. 1994), if their bias as nonpassive tracers is not prohibitive. While this has been tried elsewhere (e.g., Rennie et al. 2011) Australia has the advantages of large numbers of migrating insects (cf. the United Kingdom) but does not have mass bird migrations which can strongly bias clear air velocities (cf. the United States). Various examples of aerofauna-affected weather radar can be found in the literature (Gauthreaux et al. 2008; Bachmann and Zrnić 2008; Holleman et al. 2008; Martin and Shapiro 2007). To date, it has been found that the quality of insect-derived velocities in Australia is comparable to that of precipitation (Rennie et al. 2015, 2018), so this study also tests the impact of assimilating clear air observations. These additional observations might be expected to have a small positive impact, as demonstrated using an OSSE (Sugimoto et al. 2009). The Indian National Centre for Medium Range Weather Forecasting (NCMRWF) routinely assimilates clear air radial winds (J. George 2018, personal communication). There has been assimilation of VADs derived from clear air echoes (Michelson and Seaman 2000). However, generally this source of observations is not used, or not considered viable.

The objective of this study is to assess the impact on forecast skill of Doppler radial wind assimilation from Australian weather radar, including the clear air winds. This is an important stage in the development of the BoM's first convective-scale DA NWP system, as it determines how these observations should be used the BoM's future operational NWP systems. This paper is organized as follows. Section 2 describes the experiment and verification methods, section 3 presents the results using the different verification types, and section 4 looks at a case study.

\section{Methods}

\section{a. Radar network}

The region of interest for this study has coverage from 10 Doppler radars (Fig. 1a), although one is only partly within the domain. These are a mixture of $\mathrm{C}$ and $\mathrm{S}$ band, with 6- or 10-min scanning intervals. All radars scan over the same elevations, in $1^{\circ}$ intervals, and have single (horizontal) polarization. The radar characteristics are summarized in Table 1.

Radar observations undergo onsite and offsite processing. Onsite processing includes Doppler clutter filtering of signals with zero Doppler shift (presumed ground clutter), dual pulse repetition frequency (PRF) dealiasing (where applicable) to increase the unambiguous velocity, and noise thresholding.

Offsite processing includes further dealiasing using the 4D dealiasing method (James and Houze 2001), and classification (Rennie et al. 2015) which includes probability of detection filters, speckle and spike filters along with the naïve Bayes classification. The result is a 

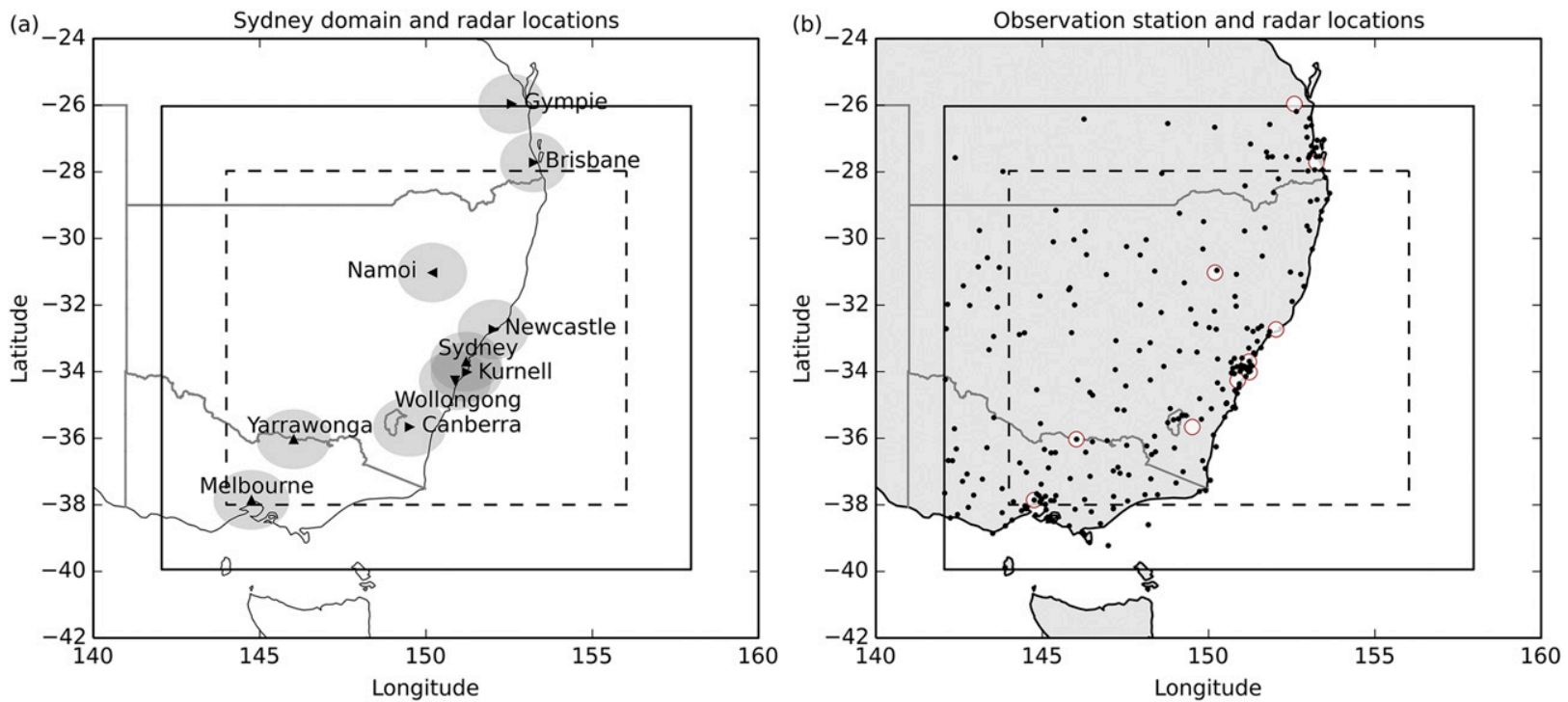

FIG. 1. (a) Map of the model domain. The solid line shows the full area, and the dashed line shows the inner fixed-resolution area of the stretched grid. The radars are shown by triangles that are oriented to point toward their name. The gray shaded circles show the $100-\mathrm{km}$ range from the radar within which observations were assimilated. (b) The location of the AWS stations (black dots) used for assimilation and verification and the radar locations (pale red circles).

dealiased velocity volume, and a classification volume, which are fed to the Observation Processing System (OPS).

\section{b. Radar OPS processing}

The OPS processing is described in detail in Simonin et al. (2014). A summary is given here. The OPS is passed radar scans at $0.9^{\circ}, 2.4^{\circ}, 4.2^{\circ}$, and $5.6^{\circ}$ elevation from all radars, at approximately $t-20 \mathrm{~min}, t$, and $t+$ $20 \mathrm{~min}$, where $t$ is the analysis hour. The observations are selected based on the classification ID for precipitation and insects. The QC configuration for observation handling follows the Met Office. Observations between 3 and $100 \mathrm{~km}$ from the radar are used. The raw velocities undergo basic QC (dealiasing by comparison with model background, removal where difference from background value is greater than $10 \mathrm{~m} \mathrm{~s}^{-1}$, filtering of isolated pixels). The velocities are then spatially averaged (superobbed) by averaging the innovations within a circle constrained by $3^{\circ}$ radial and $3-\mathrm{km}$ range limits. The superobservations are then thinned to a minimum distance of $6 \mathrm{~km}$, using the Met Office settings (Simonin et al. 2014) until a more appropriate value is established (Waller et al. 2016). The radar observation operator is a fairly simple geometric operator as described in Rihan et al. (2008) based on Lindskog et al. (2004).

The observation error is the same default as defined by Simonin et al. (2014), which is comparable to the estimated observation error derived from observation minus background statistics from the 2014 FDP (Rennie et al. 2018). It is a linear function of range, with values of $1.8 \mathrm{~m} \mathrm{~s}^{-1}$ near the radar and $2.8 \mathrm{~m} \mathrm{~s}^{-1}$ at $100-\mathrm{km}$ range.

TABLE 1. Radars providing Doppler winds for the trial, including some scan parameters and Nyquist intervals.

\begin{tabular}{lrrcccc}
\hline \hline \multicolumn{1}{c}{ Radar name } & ID & Band & Beamwidth & Scan interval (min) & Range resolution (m) & Nyquist interval (m s $\left.^{-1}\right)$ \\
\hline Melbourne & 2 & $\mathrm{~S}$ & $1^{\circ}$ & 6 & 250 & 26.2 \\
Sydney (Terrey Hills) & 71 & $\mathrm{~S}$ & $1^{\circ}$ & 6 & 250 & 26.2 \\
Wollongong & 3 & $\mathrm{~S}$ & $1.7^{\circ}$ & 6 & 500 & 39.0 \\
Kurnell & 54 & $\mathrm{C}$ & $1^{\circ}$ & 6 & 250 & 13.3 \\
Namoi & 69 & $\mathrm{~S}$ & $1.9^{\circ}$ & 10 & 500 & 39.0 \\
Canberra (Captain's Flat) & 40 & $\mathrm{~S}$ & $1.9^{\circ}$ & 6 & 500 & 39.0 \\
Newcastle & 4 & $\mathrm{~S}$ & $1.9^{\circ}$ & 6 & 500 & 39.0 \\
Yarrawonga & 49 & $\mathrm{C}$ & $1^{\circ}$ & 10 & 250 & 26.6 \\
Brisbane & 66 & $\mathrm{~S}$ & $1^{\circ}$ & 6 & 250 & 26.2 \\
Gympie & 8 & $\mathrm{~S}$ & $1.9^{\circ}$ & 6 & 250 & 39.0 \\
\end{tabular}


TABLE 2. Summary of trials.

\begin{tabular}{ll}
\hline \hline $\begin{array}{c}\text { Trial } \\
\text { ID }\end{array}$ & \multicolumn{1}{c}{ Description } \\
\hline CTRL & No radar wind assimilation \\
PRP & Assimilation of wind from precipitation echoes \\
INS & Assimilation of wind from precipitation and insect echoes \\
\hline
\end{tabular}

\section{c. NWP and assimilation configuration}

The three trials (Table 2) ran from 19 September 2017 to 5 December 2017. The period up to 1 October was considered to be for spinup and is ignored in the analysis. The NWP domain used for the trials is centered over Sydney in New South Wales (eastern Australia). The model domain is a variable grid with $1.5-\mathrm{km}$ resolution in the central region, expanding to $4-\mathrm{km}$ resolution at the boundaries. The domain contains a fairly extensive observation network and spring in this region often features severe weather in the form of convective storms, as well as large-scale weather systems. Therefore this domain offers suitable test weather cases, and observations for both assimilation and verification.

The forecast model is nested in the operational ACCESS-R (Bureau National Operations Centre 2016) $12-\mathrm{km}$ resolution system, which runs a 4D-Var analysis every $6 \mathrm{~h}$ with an update cycle. The boundary conditions are provided by the main (not update) forecast. The boundary conditions are updated at the $0300,0900,1500$, and 2100 UTC cycles (from the ACCESS-R run valid $3 \mathrm{~h}$ earlier).

The NWP suite cycles hourly, with a 1-h 4D-Var window. There is a daily reconfiguration of SST using a regional dataset (Beggs et al. 2011) and soil moisture updated from the grandparent global model. The assimilated observations include a standard set of surface observations (locations in Fig. 1b), upper air from aircraft, wind profiler, and radiosonde, satellite atmospheric motion vectors (AMV), scatterometer winds, and satellite radiances from IASI, Advanced Technology Microwave Sounder (ATMS), Cross-Track Infrared Sounder (CrIS), ATOVS, and AIRS. Quality control and thinning were applied as appropriate. The control run (CTRL) contains no Doppler radar observations. The other two trials contain precipitation-, and precipitation and insect echo-derived radar winds, respectively (PRP and INS). In the springtime in this area, the number of insect observations reaches a peak, which maximizes the impact these observations can have. At other times of year, the clear air observations may be negligible. The number of assimilated radar wind observations is shown in Fig. 2. No moisture information via latent heat nudging (a simple way to assimilate rainfall observations) is used here, although it is anticipated to be included in the operation NWP system.

The assimilation is hourly 4D-Var centered on the analysis time. The Met Office $4 \mathrm{D}-$ Var system is described by Rawlins et al. (2007). The background error covariance matrix used by 4D-Var is defined in the form of an operator. The parameters specifying this operator are derived from forecast error estimates, which are generated by a statistical analysis of a 120-element training set of forecast differences. These are differences between forecasts valid at the same time but taken from 6- and 3-h forecast lengths. They were generated by an earlier 3-hourly 3D-Var run for the Darwin domain (the same shape as the Sydney domain), which covered a period of one month. The forecasts were reconfigured to $4.5-\mathrm{km}$ horizontal grid spacing to match the grid of the linear perturbation forecast model used by the $4 \mathrm{D}$-Var. Because the construction of background error covariances distinguishes between vertical and horizontal directions, two ways of representing covariances are possible. Model level representation was used in this study as it favors a broader range of scales, emphasizing the smaller ones (Wlasak and Cullen 2014).

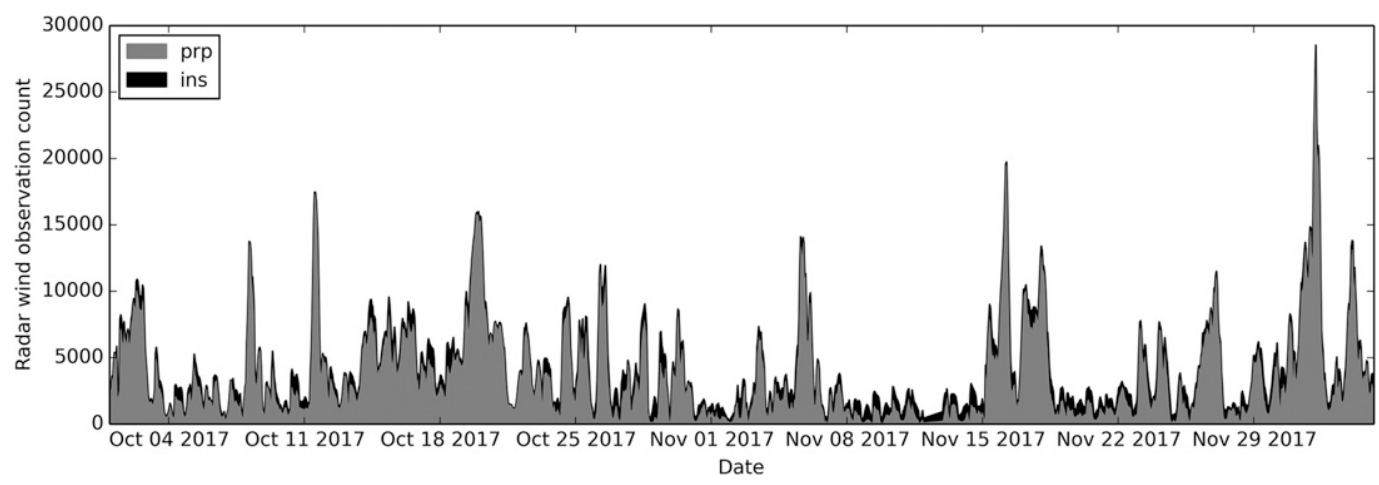

FIG. 2. The number of radial wind observations assimilated in the PRP and INS trials. The black area effectively indicates the extra observations provided by insect echoes. 
In this formulation the horizontal transform results in a spectral decomposition of the physical space, separately for each vertical level. The subsequent vertical transform operates in a spectral space spanned by horizontal modes and represents vertical covariances separately for each horizontal mode. It contrasts with the original formulation used in the 2014 FDP where for each vertical mode horizontal covariances are parameterized with a single length scale drastically reducing the number of degrees of freedom in the horizontal direction. This is the first iteration of constructing new covariances and further iterations will be made as more training data become available.

The system uses variational bias correction (VarBC) to correct for satellite radiance biases, whereby the biases are updated every cycle (Cameron and Bell 2018). Note that VarBC requires a spinup period, and may not have fully spun up over the trial period.

\section{d. Analysis methods}

Several analysis methods were selected to capture a range of vertical levels. Radar observations mostly occur within 1 - and $8-\mathrm{km}$ altitude, but there are few ways to directly observe the atmosphere at these heights that are suitable for verification, especially as Australia has a very sparse profiler network. The verification methods cover surface observations, rainfall, and cloud.

\section{1) Surface observations}

The surface verification uses an in-house package developed to compare the model with observations from automatic weather stations (AWS). The AWS station locations are shown in Fig. 1b. Model fields are interpolated to the observation location, and corrections made for height differences between the AWS and the model orography. The observed quantities are 2-m temperature, 2-m dewpoint, 10-m wind, and surface pressure. Results can be produced for area-averaged time series, time-averaged station quantities, or area averaged by time of day, for various forecast lengths and basetimes.

\section{2) FSS}

The fractions skill score (FSS) (Roberts and Lean 2008) makes a comparison of the number of rainfall pixels within a boxed region (window), where a pointbased comparison will perform poorly due to mislocation of precipitation. The skill score is defined for a window of size $n$ as

$$
\mathrm{FSS}_{(n)}=1-\frac{\operatorname{MSE}_{(n)}}{\operatorname{MSE}_{(n) \mathrm{ref}}},
$$

where

$$
\operatorname{MSE}_{(n)}=\frac{1}{N_{x} N_{y}} \sum_{i=1}^{N_{x}} \sum_{j=1}^{N_{y}}\left(O_{(n) i, j}-M_{(n) i, j}\right)^{2} .
$$

Here $O_{(n) I, j}$ and $M_{(n) I, j}$ are the observed and model forecast fractions of a binary field of incidence of rainfall over a given threshold, in a domain of $N_{x} \times$ $N_{y}$. A forecast with $\operatorname{FSS}(n)=1$ is a forecast with perfect skill over a window size of $n . \mathrm{MSE}_{(n) \text { ref }}$ represents the largest possible MSE. As FSS is a skill score, the mean FSS of multiple forecast periods is calculated as

$$
1-\overline{\operatorname{FSS}}_{(n)}=1-\frac{\overline{\operatorname{MSE}}_{(n)}}{\overline{\operatorname{MSE}}_{(n) \mathrm{ref}}},
$$

where the MSE values are replaced with the sample means.

FSS is calculated using two observation types: groundbased radar composites and satellite precipitation.

\section{(i) Radar accumulations}

The composites from BoM operational Rainfields2 (Seed et al. 2007) are a blend of radar and rain gauge data accumulation in a 30-min period, which should provide the highest accuracy. However, the quality control is an earlier version than that used for the assimilated radar wind, so it is expected that some ground clutter issues will be worse. Three composites, for the Sydney area, the Melbourne area, and the Brisbane area, provide partial coverage for the fixed-grid region of the model domain. These three composites were aggregated into hourly rainfall accumulations and regridded from the individual gnomonic projections ( $2-\mathrm{km}$ resolution) onto the $0.0135^{\circ}$ resolution model grid, putting all composites (not overlapping) into the same array. As one radar (Canberra) often has severe sea clutter issues, times when this was observed were noted and the area containing the clutter was masked, unless it was difficult to discriminate it from some nearby rainfall.

For the radar comparison, the model data are masked to match the availability of data in the radar composite prior to calculation of FSS. Figure 3 shows the FSS verification region with respect to the model domain, and the mask of the radar composite, assuming all radars were online.

\section{(ii) Satellite accumulations}

The Global Precipitation Mission (GPM) (Huffman et al. 2017) produces half-hourly rainfall rates $\left(\mathrm{mm} \mathrm{h}^{-1}\right)$ on a $0.1^{\circ}$ grid. The "late run" IMERG dataset was used. This was cut down to the Sydney fixed-resolution grid 
$3 \mathrm{hr}$ forecast from $201711162100 \mathrm{Z}$
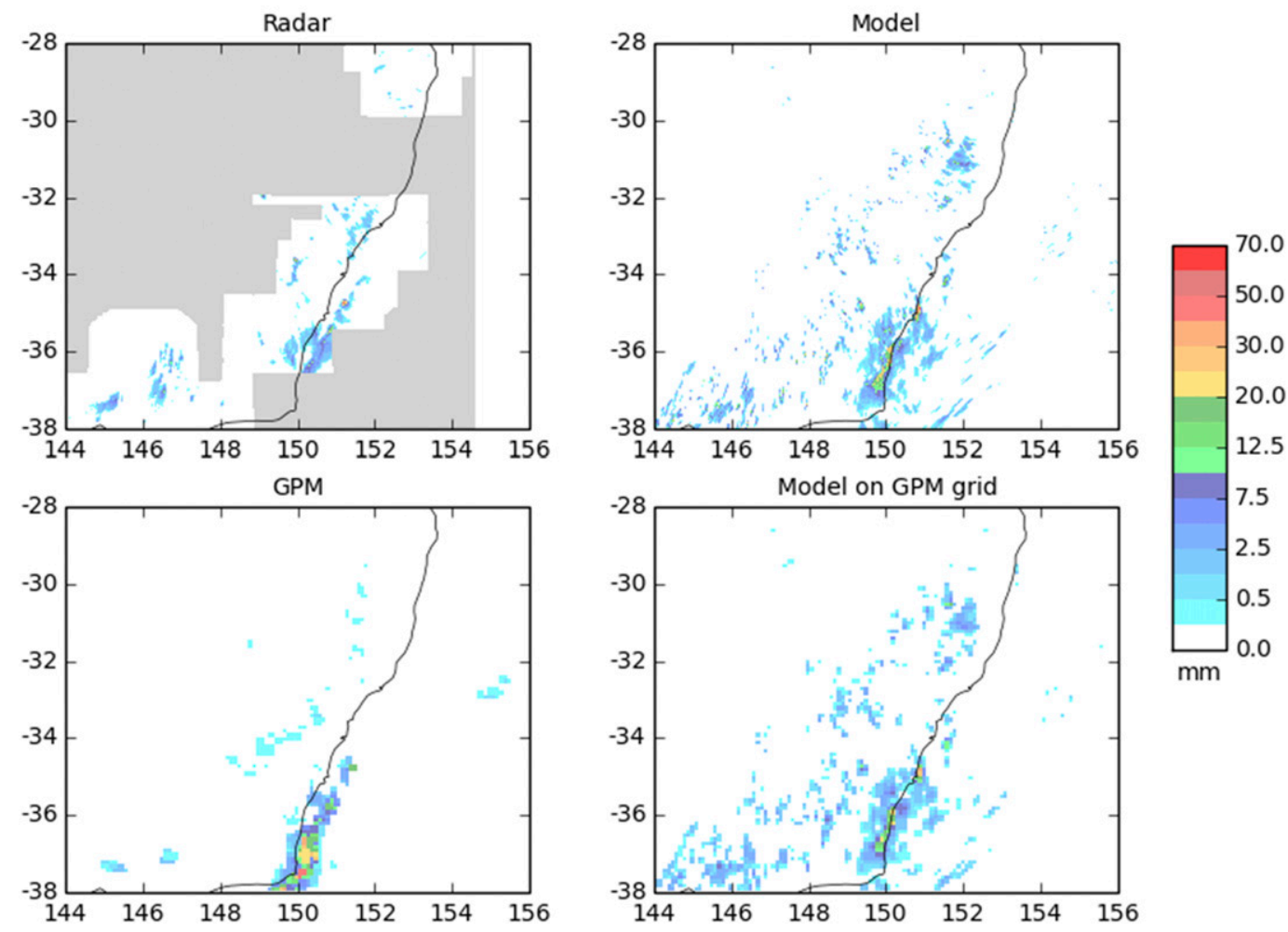

FIG. 3. (top) Plot of 1-h rainfall accumulation (mm) from radar and CTRL model data for 0000 UTC 17 Nov 2017 after a 3-h forecast. (bottom) Plot of GPM and regridded model data.

area, and two half-hourly files were averaged to produce an equivalent hourly accumulation.

\section{(iii) Model data}

The model precipitation is prepared in several steps. First, the fields of accumulated rainfall and accumulated snowfall are added together. Then the total precipitation field is cut down to the fixed-grid area for which observations exist (i.e., smaller for radar than GPM), and split into hourly accumulations.

To compare with the GPM, the model precipitation was regridded using an area-weighted gridder from Iris (Met Office 2017) to the GPM grid. An example of regridded model data is shown in Fig. 3.

For the FSS calculation a threshold of $0.2 \mathrm{~mm}$ was applied (per hour for radar and per $3 \mathrm{~h}$ for GPM), below which it was assumed that the observations had effectively no rainfall. The observed rain rate thresholds were set to be $0.5,1.0,2.0,4.0,8.0,12.0$, and $16.0 \mathrm{~mm} \mathrm{~h}^{-1}$. For these rain rates, the percentile was calculated using SciPy (Oliphant 2007) "percentileofscore" from the stats package. From this, the rain rates for the equivalent percentile were calculated for the model data, on a caseby-case basis. In this way the relative percentiles are matched for observations and model even if the rainfall distributions are different. For GPM, cases where there was no observed threshold-exceeding rain rate instance within $1^{\circ}$ from the domain boundary were excluded from the FSS analysis to avoid the double penalty of false positives outside of the domain.

FSS was calculated every 3 hours between 1 October and 5 December, for a range of window sizes and observed rain rates, for forecast lengths of 3 (radar only), 6, 12, and $18 \mathrm{~h}$.

The distributions of model rain rates matched to observed rain rates for the CTRL experiment is shown in Fig. 4, for both radar and GPM. Each panel corresponds to an observation rain rate, and the histogram is of the values of the model rain rate that were percentilematched to that observation rain rate, for all cases. This shows that sometimes the rain rates were very different, although on average the values are similar, as indicated by the mean and mode values.

\section{3) SYNTHETIC SATELLITE IMAGERY COMPARISON \\ (i) Rationale}

Verification of high-resolution models is complicated by displacement errors: the ability of the models to 
Radar rainrate vs model rainrate for forecast length $03 \mathrm{~h}$

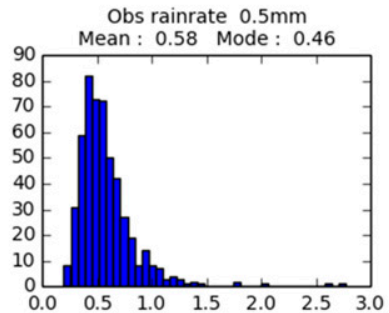

Obs rainrate $2.0 \mathrm{~mm}$

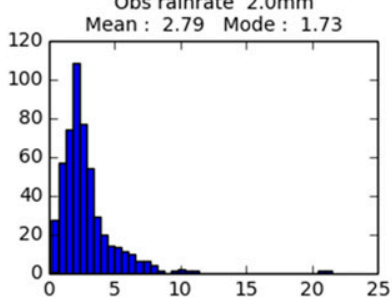

Obs rainrate $8.0 \mathrm{~mm}$

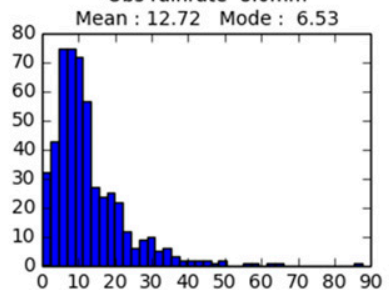

Obs rainrate $16.0 \mathrm{~mm}$

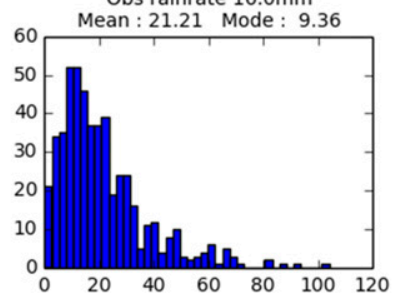

Obs rainrate $4.0 \mathrm{~mm}$

Obs rainrate $12.0 \mathrm{~mm}$
GPM rainrate vs model rainrate for forecast length $03 \mathrm{~h}$
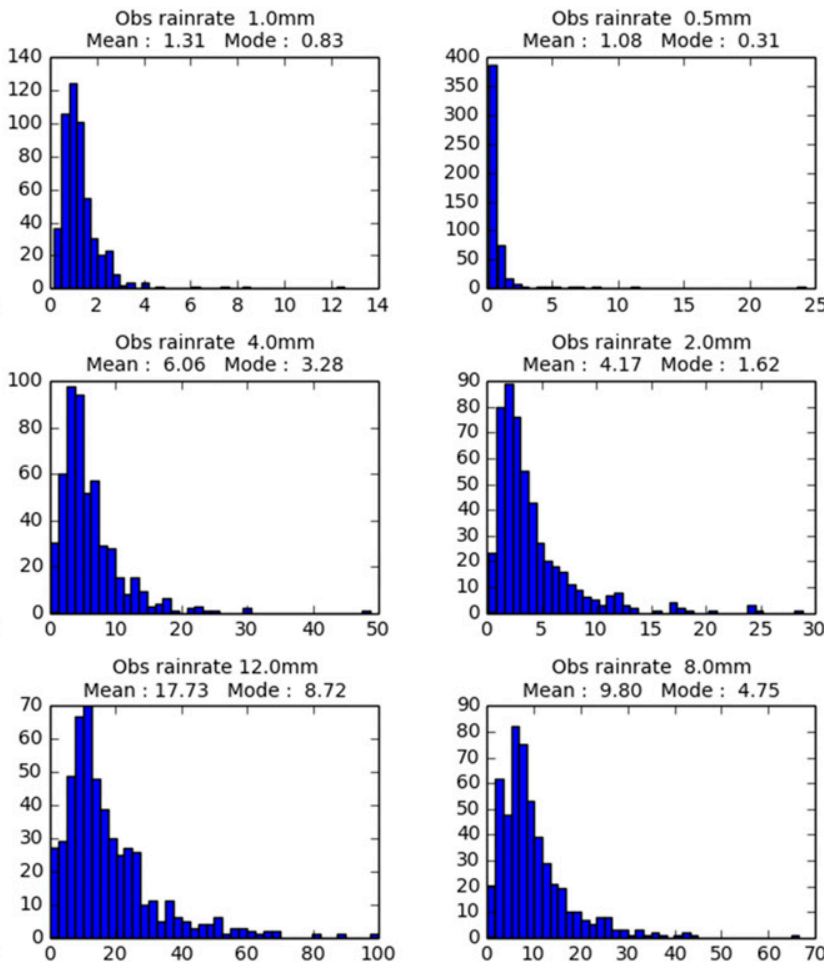

Obs rainrate $2.0 \mathrm{~mm}$

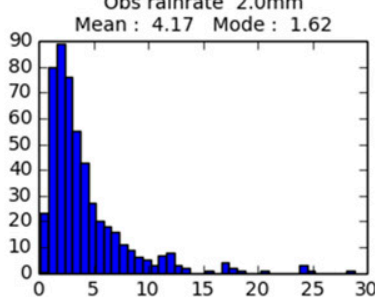

Obs rainrate $8.0 \mathrm{~mm}$

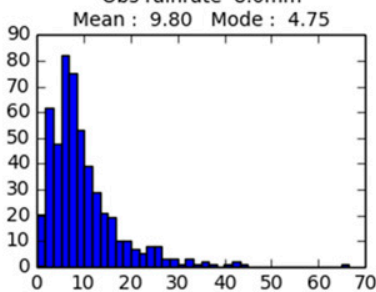

Obs rainrate $16.0 \mathrm{~mm}$

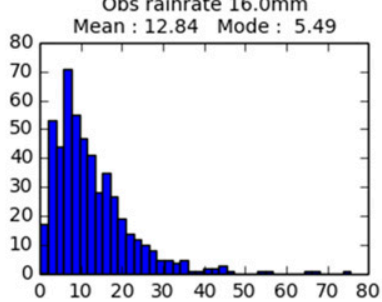

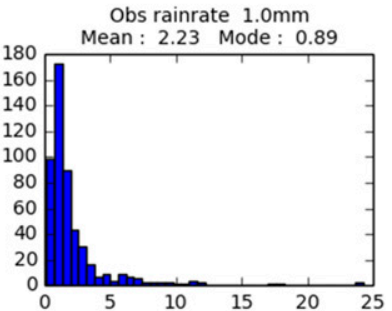

Obs rainrate $4.0 \mathrm{~mm}$

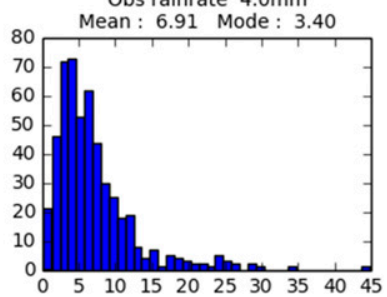

Obs rainrate $12.0 \mathrm{~mm}$

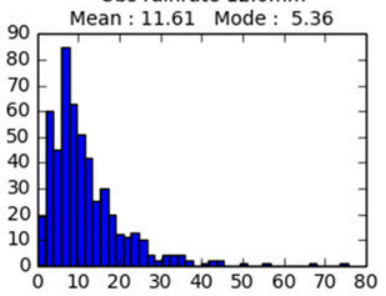

FIG. 4. Histograms showing distribution of model rain rates matched to the observed rain rate via equivalent percentiles. Each panel corresponds to an observation rain rate. Mode and mean values for the histograms are shown above each panel. The mode is estimated via fitting an inverse-normal distribution to the histogram. The two left columns are for radar, and the two right columns are for GPM.

produce realistic and useful synoptic forecasts but with misplaced features that result in double penalties in the usual grid-based metrics. Several strategies have been developed or are under development to deal such errors (e.g., Roberts and Lean 2008). The philosophy considered here is based on the idea that the model should be able to produce a realistic probability distribution function (PDF) for observed fields over a sufficiently long period encompassing a large number of synoptic situations regardless of whether it is able to accurately predict the placement of all synoptic features. To assess how well a model satisfies these criteria requires an observational field that is easily calculated from the model with a minimal number of assumptions and that can be made available over as much of the model domain as possible, preferably all of it. Synthetic infrared imagery is ideal for this purpose; the corresponding Himawari imagery is available over the model domain every $10 \mathrm{~min}$ and the radiative transfer calculation is easy, relatively realistic, and utilizes well-understood physics. Infrared satellite imagery is routinely used by operational forecasters because it provides a readily interpretable synthesis of the overall state of the atmosphere at a given time, and the synthetic imagery from the model performs the same function for the model. Another advantage of the infrared channel is that it saturates very quickly for small cloud condensate path (i.e., only very optically thin cloud is nonblack) so that the algorithms are not very sensitive to the details of the clouds microphysical properties, making it a good field for assessing the large-scale horizontal distributions of model cloud and water vapor fields. 


\section{(ii) The data and its processing chain}

Model forecast fields were used to calculate synthetic satellite imagery offline using the archived model cloud fields and using the model's physics parameterization schemes for cloud optical properties for every hour of every forecast over the trial period. The calculations are physically based radiative transfer calculations that use the Himawari-8 infrared channel spectral response function and take account of the satellite's view angle relative to the grid. As it is a two-dimensional calculation, which assumes independent profiles, it is unable to fully account for the three-dimensional radiative effects due to cloud variations in neighboring profiles that should be accounted for at model resolutions comparable to the height of the cloud fields. This affects the accuracy of the results for small high clouds and large satellite view angles. To fully account for these, a fully three-dimensional radiative transfer code along with all of its attendant complexity and computational burden would be required.

The empirical PDF of the infrared brightness temperatures was generated for each forecast image by calculating frequency histograms with $1-\mathrm{K}$ bins for comparison with those calculated from the Himawari data interpolated onto the model grid and stored as a function of base date/time and forecast hour to enable partitioning and slicing of the data in the subsequent analyses.

\section{(iii) Definition of the metrics}

HBias corresponds to the standard bias difference between the model and corresponding satellite field calculated from the accumulated histograms. For each valid time $v$ and forecast hour $f$ :

$$
B_{v f}=\frac{\sum_{T} M_{v f}(T)-\sum_{T} S_{v}(T)}{\Delta T},
$$

where the sum over $T$ represents the sum over all histogram bins and $\Delta T$ is the bin size, $M_{v f}(T)$ is the model histogram for the $f$ hour forecast for the valid time $v$, and $S_{v}(T)$ is the corresponding satellite histogram for the same valid time.

Chisquare corresponds to the standard mean square difference between the model and corresponding satellite field calculated from the accumulated histograms:

$$
X_{v f}^{2}=\frac{\sum_{T}\left[S_{v}(T)-M_{v f}(T)\right]^{2}}{S_{v}(T)},
$$

where the sum over $T$ represents the sum over all histogram bins with satellite nonzero counts.
The Kolmogorov-Smirnov integral (KSI) is the integral of the absolute difference between the cumulative distribution functions for the two distributions being compared which can be expressed as a sum over all histogram bins:

$$
\mathrm{KSI}_{v f}=\sum_{T}\left|M_{v f}^{C}(T)-S_{v}^{C}(T)\right| \Delta T,
$$

where $M_{v f}^{C}$ and $S_{v}^{C}$ are the cumulative frequencies derived from the histograms for model and satellite, respectively.

The two sample Kolmogorov-Smirnov metric (KS score) is defined as the maximum difference between the cumulative distribution functions. The significance value (KS $p$ value) is calculated using a simple formula (Massey 1951):

$$
D_{v f}=\max _{T}\left|M_{v f}^{C}(T)-S_{v}^{C}(T)\right| .
$$

The mean scores were averaged over either valid time or forecast hour. Confidence intervals were calculated via an empirical bootstrap process. The distribution of sample means from 1000 samples with replacement and the 95 th and 5 th percentiles selected.

\section{Results}

\section{a. FSS}

The mean FSS is calculated across the trial period from 1 October 2017 to 5 December 2017 (523 forecasts), for separate rain rates, window sizes, and forecast lengths. A cross section of results is shown in Fig. 5, with FSS as a function of forecast lengths, covering a range of rain rates and window sizes. The FSS increases with window size as expected and decreases with forecast length. The PRP and INS trials appear to do better than CTRL at 3-h forecast lengths, but results are mixed at longer forecast lengths. The differences in mean FSS between experiments are small, though the spread is often larger for larger rainfall rates. However, the large rain rates have fewer cases, so the sample size may contribute to the difference seen. Skill is usually assumed to be slightly over 0.5. Based on Roberts and Lean (2008) the skill is calculated as $0.505-0.525$, decreasing with increasing rain threshold. For radar, at low rain rates, the skill is apparent at $15-30 \mathrm{~km}$, depending on forecast length. For high rain rates, skill is achieved at $150 \mathrm{~km}$. For GPM, skill is also seen at the minimum range of $50 \mathrm{~km}$, but at high rain rates, skill is apparent at $200-300 \mathrm{~km}$. The scale at which the forecasts show skill isn't shown 
FSS by forecast length for Radar
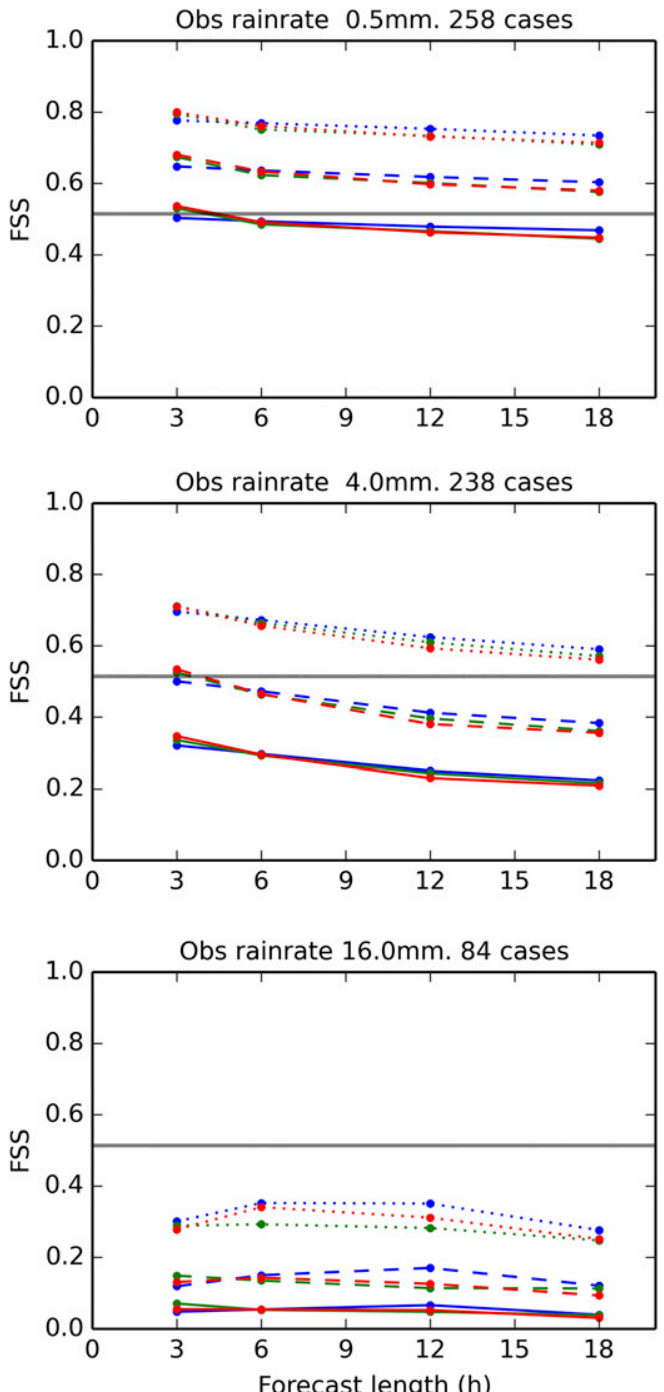

\begin{tabular}{|c|c|c|c|c|c|}
\hline$\bullet \mathrm{ctrl}$ & $14 \mathrm{~km}$ & $\bullet$ prp & $14 \mathrm{~km}$ & $\leftrightarrow$ ins & $14 \mathrm{~km}$ \\
\hline •-• & $52 \mathrm{~km}$ & 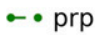 & $52 \mathrm{~km}$ & ins & $52 \mathrm{~km}$ \\
\hline 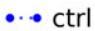 & $127 \mathrm{~km}$ & rp & $127 \mathrm{~km}$ & $\cdots$ ins & $127 \mathrm{~km}$ \\
\hline
\end{tabular}

FSS by forecast length for GPM
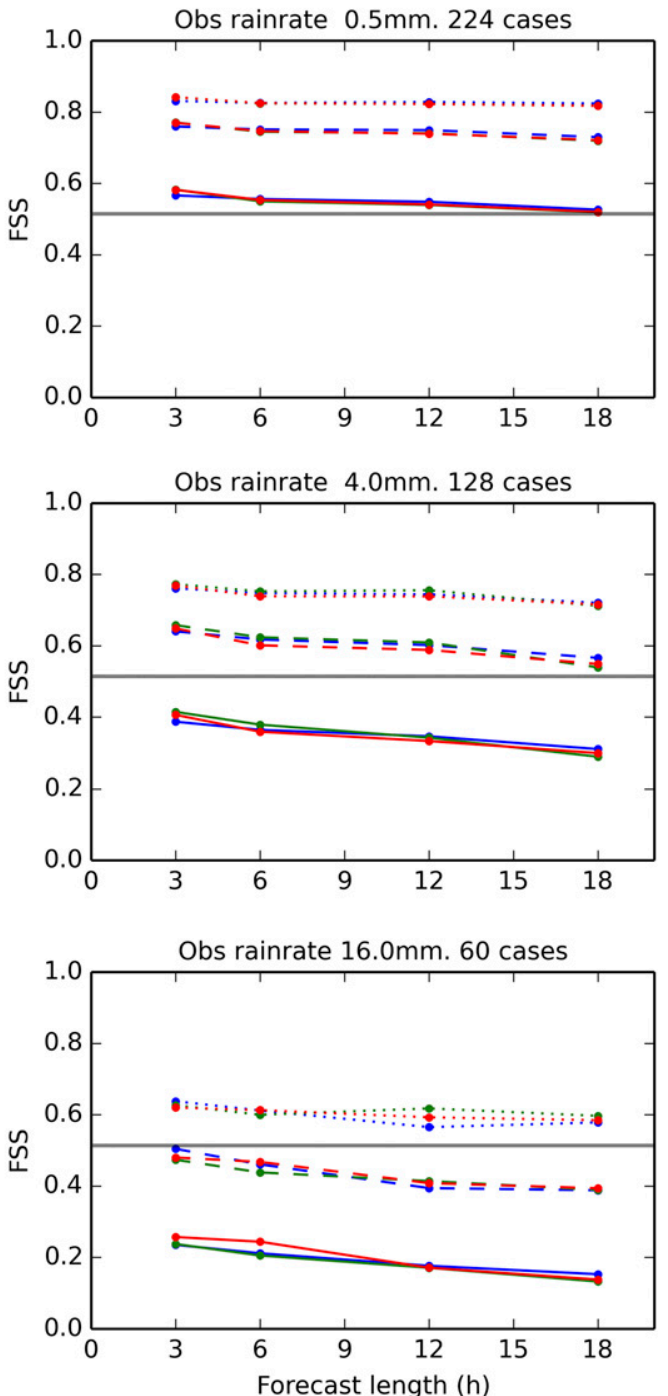

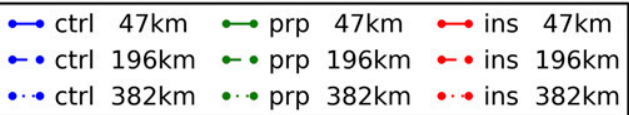

FIG. 5. The average FSS for all three runs as a function of forecast length, over the experiment period. Three rain rates (lowest, middle, and highest values) are represented in the vertical panel order as per the panel subheadings. Three window sizes (lowest, middle, and highest) are shown in each panel, indicated by line pattern as per the legend. The gray horizontal line represents the value at which FSS is considered skillful (Roberts and Lean 2008).

explicitly, as the difference between the trials is negligible in practice.

The significance of FSS differences was estimated using a Monte Carlo approach. A total of 1000 subsamples of approximately half the distribution were selected using random numbers. The mean and standard deviations of these were calculated. The significance of the difference was estimated using a two-tailed $t$ test. Most differences were significant to $95 \%$. A scorecard example in Fig. 6 shows the mean differences by window and rain rates between all trials. The verifications against radar and GPM do not always show agreement, and also often change sign with rain rates and forecast length. Figures 5 and 6 both show that the radar runs did better at $3 \mathrm{~h}$, particularly at low rain rates. However, at long forecast lengths, the control was generally better. GPM and radar disagreed on the better results for 
Radar Precipitation - Control
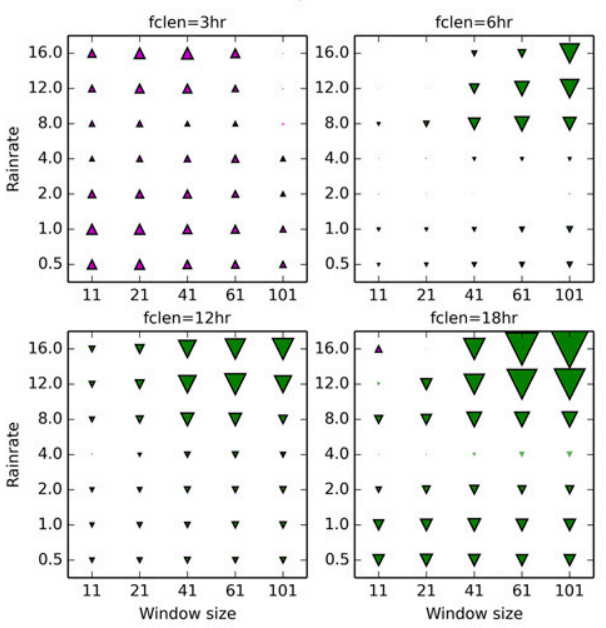

Radar Insects - Control
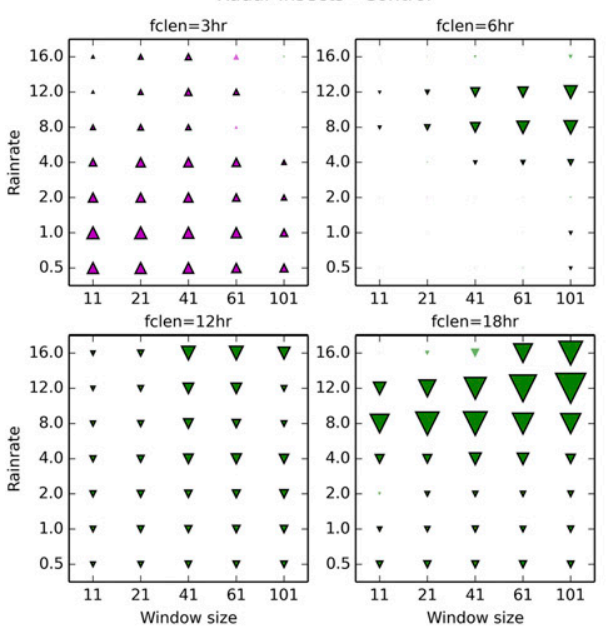

Radar Precipitation - Insects
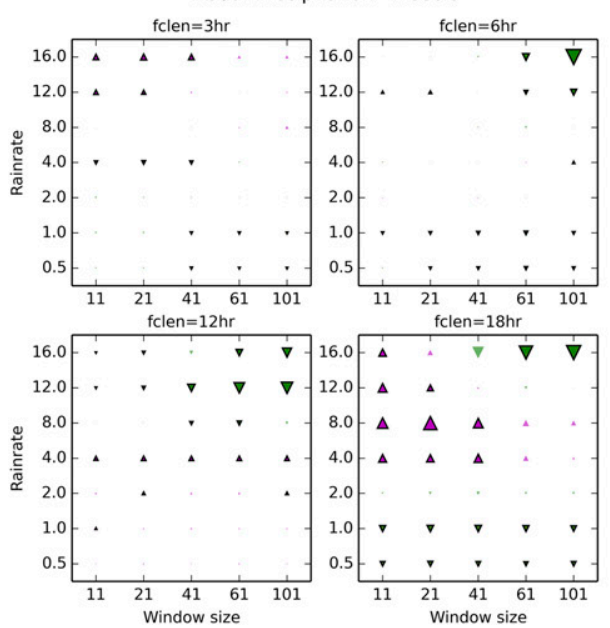

GPM Precipitation - Control

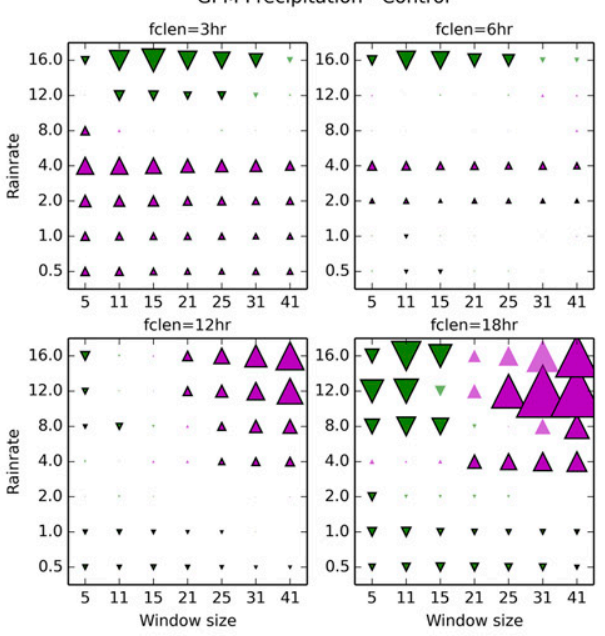

GPM Insects - Control
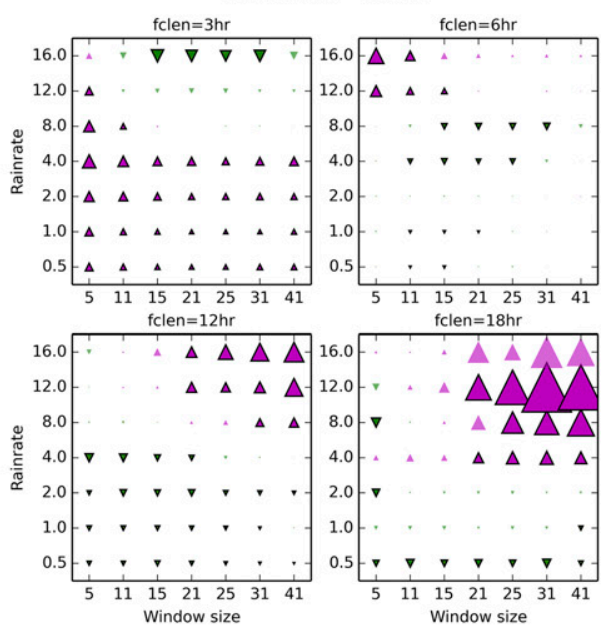

GPM Precipitation - Insects

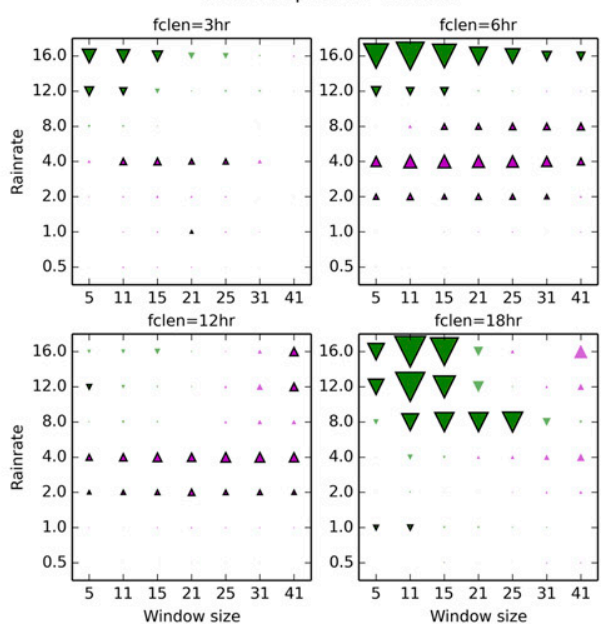

FIG. 6. The relative size and significance of the difference in mean FSS values between trials for different rain rates and window sizes. Radar is shown on the left, and GPM is shown on the right; hence the right column represents the differences between the lines in Fig. 4. Positive differences are upward magenta arrows, and negative differences are downward green arrows. Significant differences are outlined in black, and nonsignificant differences are paler. 

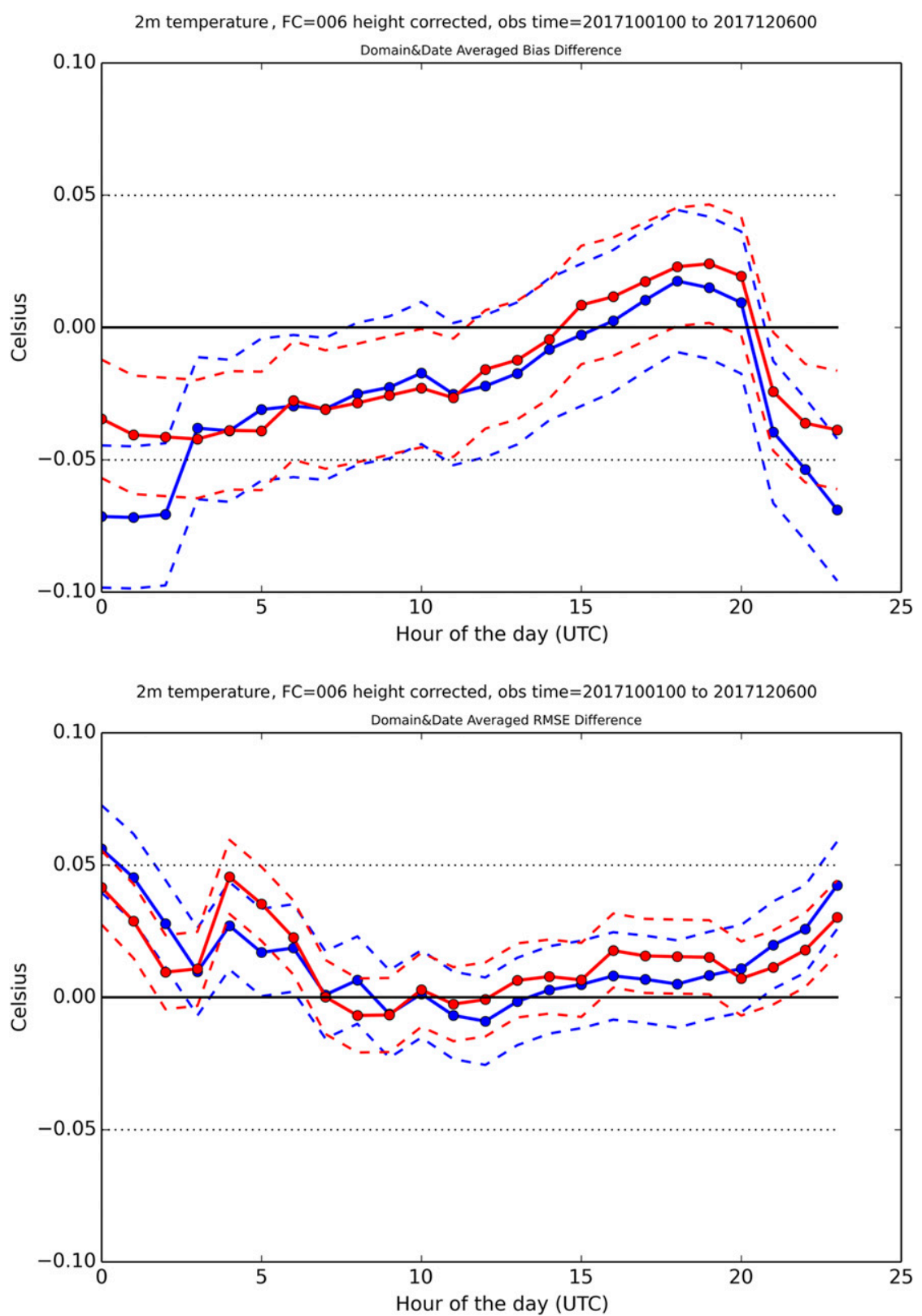

FIG. 7. The 2-m temperature difference in bias and RMSE. Blue is PRP-CTRL, and red is INS-CTRL. Dashed lines indicate the standard deviation. The difference in bias and RMSE from CTRL is very small compared to the bias and RMSE values on the order of $1^{\circ}-2^{\circ} \mathrm{C}$. The differences are not generally significantly different. Nor does one trial overall perform better than another. This example is typical of the results.

high rain rates, where sample size may be a factor. The PRP and INS runs were more similar to each other than compared to the control.

\section{b. Surface observation verification}

The surface verification against observations (wind components and wind speed within various thresholds, temperature, and dewpoint) showed little difference among the trials. There were clear diurnal cycle and spatial biases in the forecast, which dominated the verification. These are largely a function of the model, and so do not invalidate the comparison of assimilation experiments, but are much larger than the effect of assimilation differences. An example of the difference in 2-m temperature is shown in Fig. 7, with an average by hour of day across all dates and stations. 


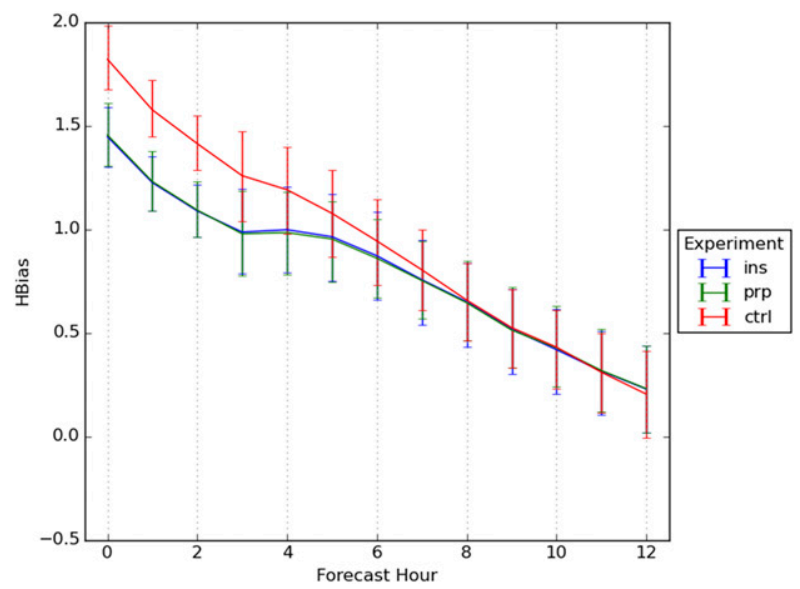

FIG. 8. Mean (over all valid times in the trial period) of the domain bias for the three experiments as a function of the time from the beginning of the individual forecasts. The error bars represent the bootstrap-derived confidence intervals.

These differences are only $1 \%-10 \%$ of the magnitude of the values being compared.

The analysis was also repeated using only 117 AWS within $100 \mathrm{~km}$ of the radars (i.e., where the radar observations might directly have an impact). This gave very similar results to the whole-domain analysis, so results are not shown here. Additionally, a comparison of statistics at 3- and 6-h forecasts did not show improvement within the first few hours, as could be seen with FSS.

The general conclusion drawn from all the verification output was that the INS run was more different from the control than the PRP run, a realistic outcome from the assimilation of additional radar wind observations. However, the effect on surface parameters was very small compared to the model diurnal cycle bias effects. Overall, this is not an unexpected result. Radar winds are primarily at a height of $1-8 \mathrm{~km}$ and will not strongly impact surface fields.

\section{c. Synthetic imagery verification}

Figure 8 shows the mean over the period of the domain histogram bias (HBias) in brightness temperatures for the three experiments. The two radar experiments are better than CTRL over the first 6-7 h of the forecasts and significantly better over the first two hours when the much larger frequency of forecasts results in smaller confidence intervals. After $8 \mathrm{~h}$ there is no difference between the histogram biases. Note that the HBias starts positive implying a systematic lack of cold high cloud but then drops throughout the forecasts to be negative (too much cold cloud) after about $18 \mathrm{~h}$.

Although HBias indicates better results for PRP and INS over the first few hours of the forecast the plots

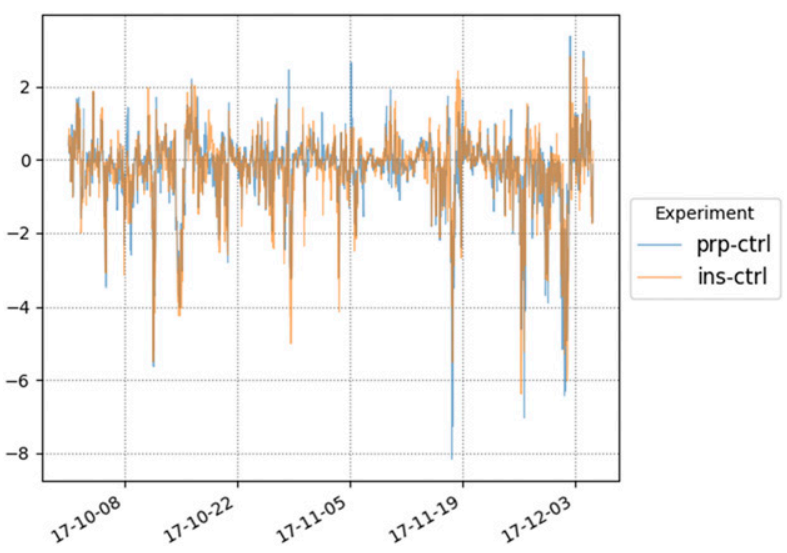

FIG. 9. The difference from CTRL for the domain bias (Hbias) calculated from Eq. (4) and averaged over all forecast hours for each valid time in the trial period for the three experiments.

against base date suggest that this is dominated by a number of periods where they show larger negative bias (Fig. 9). At the same time the chisquare plot in Fig. 10 suggests the perturbation experiments are actually worse over the first few hours, although there are no statistically significant differences among the 3 experiments. The PRP and INS tend to behave more like each other than they do like CTRL for the first $10 \mathrm{~h}$.

\section{Case study: 26 October 2017}

To better evaluate the effects of the additional observations, a number of case studies of heavy rainfall events were viewed and one was selected for display here as a case study.

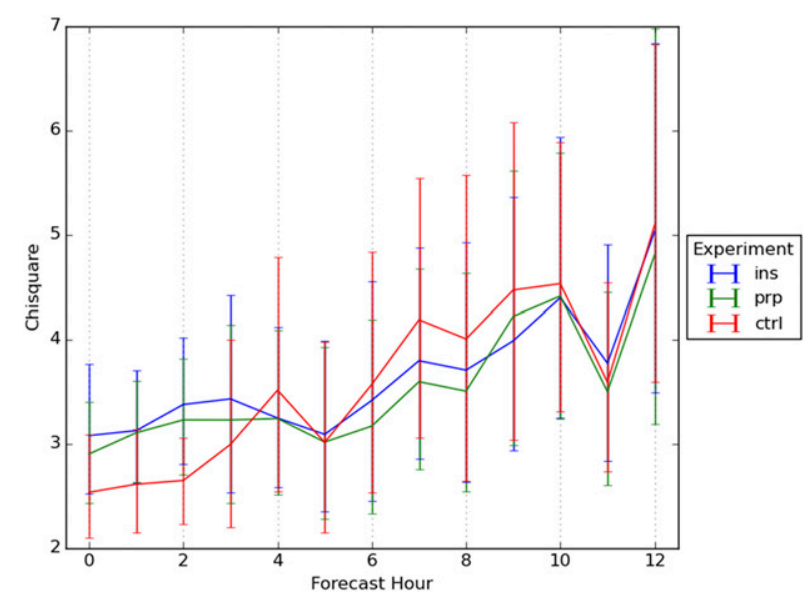

FIG. 10. Mean (over all valid times in the trial period) chisquare scores for the three experiments as a function of the time from the beginning of the individual forecasts. While there are no statistically significant differences among the three experiments, the two perturbation experiments tend to behave more like each other than like the control. 
60 min accumulated precipitation valid $201710260600 \mathrm{Z} \mathrm{T}+6 \mathrm{hr}$

Radar rainfall

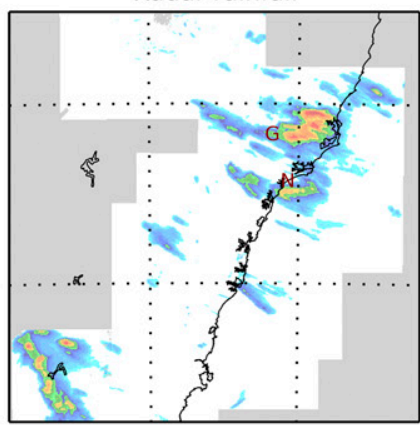

ctrl run

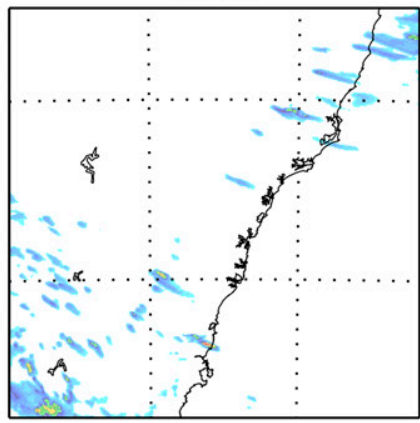

prp run

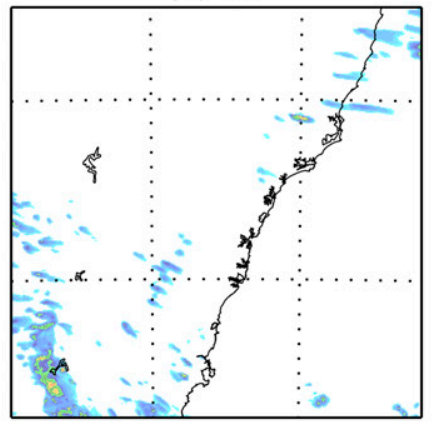

ins run
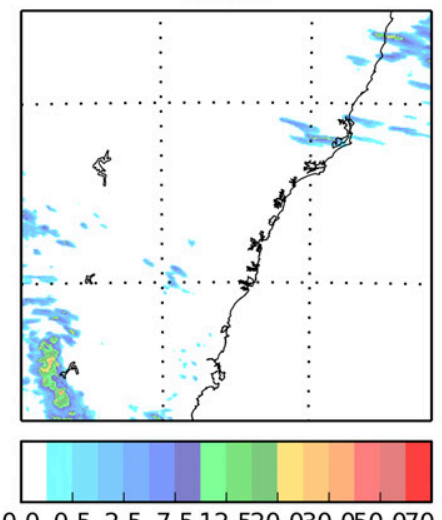

60 min accumulated precipitation valid $201710261200 \mathrm{Z} \mathrm{T}+6 \mathrm{hr}$

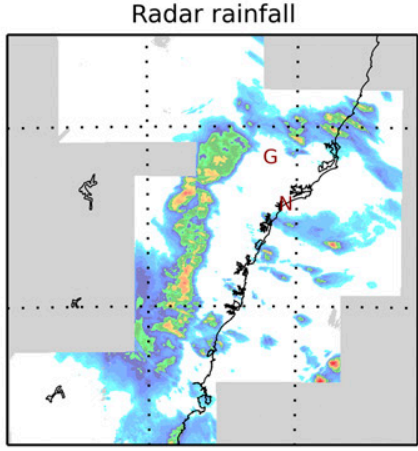

ctrl run

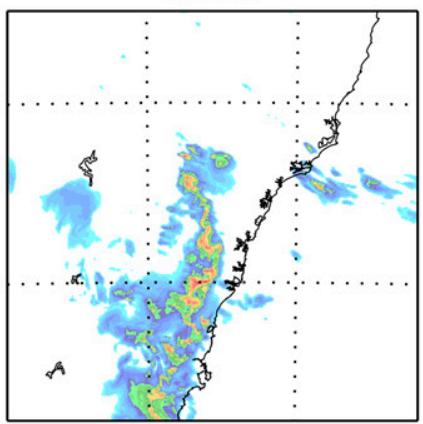

prp run

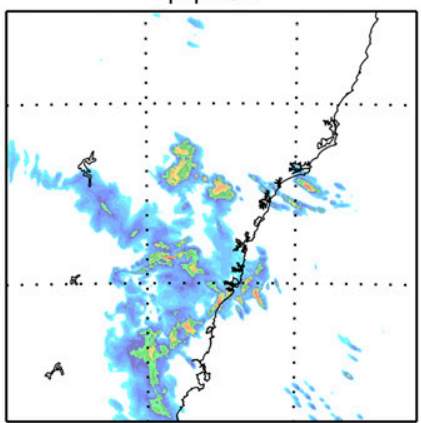

ins run
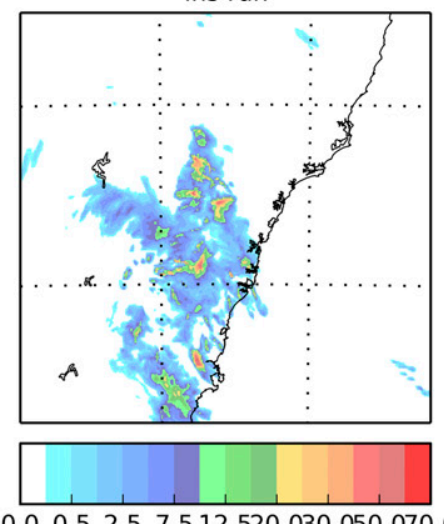

FIG. 11. (left) At 0600 UTC 26 Oct 2017, the 6-h forecast. Radar (shown at top left) shows a heavy hail event along the northern New South Wales coast and a line of showers heading eastward from the southeast corner of the panel. (right) At 1200 UTC 26 Oct 2017, the 6-h forecast from 0600 UTC. A line of showers is heading eastward toward the coast. Gresford and Newcastle locations are shown in the radar panels with a "G" and "N," respectively. 
A severe hail event occurred on 26 October 2017, where 5-cm hail was reported in Gresford and a large amount of hail fell in Newcastle. Figure 11 shows the storm several hours after initiation. All runs missed this storm, which suggests the initiation was not captured. The line of showers in the southwest corner is better located in the PRP and INS runs than the CTRL runs at 0600 UTC. However, later in the forecast the line of showers had moved northward and all trials had the line ahead of observations. Furthermore, the line was much better organized in the CTRL run than the other runs.

Figure 11 also shows the situation at a later time, where a line of showers is heading toward the coast. All trials have the rain less organized. Later in the day (1400 UTC) the CTRL run is better at long lead time, but at shorter lead times the PRP and INS runs are better. The CTRL run kicks off a storm in the north that is much reduced in PRP and INS, where observations show little rain.

This case study shows that although the verification metrics showed little statistical difference in forecast skill, the forecasts themselves look obviously different. Furthermore, the extra observations were little help in a case where a large storm failed to initiate.

\section{Summary}

A two-month trial with and without assimilating Doppler radar winds has been analyzed using a range of techniques. Although the forecasts are obviously altered by the addition of new observations, the objective assessment techniques generally do not show great differences among the trials. To summarize

- Objective verification against surface observations shows no significant difference among the trials, with results dominated by model biases.

- Fractions skill score was assessed using both radar composites and GPM data. The trials all showed a level of skill. The differences among the trials were small, but Monte Carlo estimates of significance demonstrated that many of these differences were significant. However, there was no clear winner among the trials, and often the trial that performed better against radar performed worse against GPM. It was clear that the PRP and INS trials were more similar than the CTRL.

- Synthetic cloud analysis showed the PRP and INS runs to have a lower mean bias, but the chisquare results suggest CTRL is better over the first few hours of the forecast.

- From case study analysis, generally it is possible to find times when the CTRL was either better or worse than PRP or INS, even within the same forecast. Often the forecasts are different, but none are consistently better, much as three ensemble members might differ.

The verification at the surface and aloft with rain and clouds showed that differences between the trials were statistically small on average, although there could be large differences between individual forecasts. Overall, the results suggest that the impact of radar wind data in this trial is largely neutral. This is a positive result in that the assimilation of radar wind can proceed within the context of operational NWP development. While this result does not reflect the improvements that have been seen in some other studies, it does reflect the conclusion of Montmerle and Faccani (2009) that "impacts on forecast scores against conventional data on large samples in space and in time are mostly neutral." Note also that we focus on the longer lead times that will be used operationally, rather than the very short lead times used for numerical nowcasting, and on the broader analysis rather than specific storms, since this system will be used operationally in a much broader context than storm weather.

This study represents one aspect of developing the BoM's first operational convection-allowing system with data assimilation, so it is anticipated that future system improvements to the data assimilation, or upgrades to the radars to improve observation quality, will lead to improvements in forecast skill. There are plans to use correlated observation errors for a future version of the high-resolution NWP system, based on the work of Waller et al. (2016). The datasets derived from extended trials like this one will be used to calculate such errors. Regarding the use of VarBC, it is debatable if the best approach is to update the bias corrections from within the limited area system, where observations are limited and it may take a long time to spin up. In future, the system is likely to use VarBC information from the parent global NWP system instead, once that is available.

Acknowledgments. This research was undertaken with the assistance of resources and services from the National Computational Infrastructure (NCI), which is supported by the Australian Government. Thanks to Tan Le, Gary Dietachmayer, and Shaun Cooper for assistance with various technical issues, advice, and feedback.

\section{REFERENCES}

Aksoy, A., D. C. Dowell, and C. Snyder, 2009: A multicase comparative assessment of the ensemble Kalman filter for assimilation of radar observations. Part I: Storm-scale analyses. Mon. Wea. Rev., 137, 1805-1824, https://doi.org/10.1175/2008MWR2691.1. 
Bachmann, S., and D. Zrnić, 2008: Suppression of clutter residue in weather radar reveals birds' corridors over urban area. IEEE Geosci. Remote Sens. Lett., 5, 128-132, https://doi.org/10.1109/ LGRS.2008.915601.

Ballard, S. P., Z. Li, D. Simonin, and J. F. Caron, 2016: Performance of 4D-Var NWP-based nowcasting of precipitation at the Met Office for summer 2012. Quart. J. Roy. Meteor. Soc., 142, 472-487, https://doi.org/10.1002/qj.2665.

Beggs, H., A. Zhong, G. Warren, O. Alves, G. Brassington, and T. Pugh, 2011: RAMSSA-An operational, high-resolution, Regional Australian multi-sensor sea surface temperature analysis over the Australian region. Aust. Meteor. Oceanogr. $J .$, 61, 1-22, https://doi.org/10.22499/2.6101.001.

Bureau National Operations Centre, 2016: APS2 upgrade to the ACCESS-R numerical weather prediction system. BNOC Operations Bull. 107, Bureau National Operations Centre, 29 pp., http://www.bom.gov.au/australia/charts/ bulletins/apob107-external.pdf.

_ 2018: APS2 upgrade of the ACCESS-C numerical weather prediction system. NOC Operations Bull. 114, Bureau National Operations Centre, 33 pp., http://www.bom.gov.au/australia/ charts/bulletins/BNOC_Operations_Bulletin_114.pdf.

Cameron, J., and W. Bell, 2018: The testing and implementation of variational bias correction (VarBC) in the Met Office global NWP system. Met Office, 22 pp., https://digital.nmla.metoffice. gov.uk/digitalFile_a3d48fa7-14ea-4695-a329-221389a5371d/.

Choi, Y., G.-H. Lim, and D.-K. Lee, 2013: Radar radial wind data assimilation using the time-incremental 4D-Var method implemented to the WRFDA system. Tellus, 65A, 19677, https:// doi.org/10.3402/tellusa.v65i0.19677.

Chung, K.-S., I. Zawadzki, M. K. Yau, and L. Fillion, 2009: Shortterm forecasting of a midlatitude convective storm by assimilation of single-Doppler radar observations. Mon. Wea. Rev., 137, 4115-4135, https://doi.org/10.1175/2009MWR2731.1.

Crook, N. A., and J. Sun, 2002: Assimilating radar, surface and profiler data for the Sydney 2000 Forecast Demonstration Project. J. Atmos. Oceanic Technol., 19, 888-898, https://doi.org/ 10.1175/1520-0426(2002)019<0888:ARSAPD>2.0.CO;2.

de Haan, S., 2013: Assimilation of GNSS ZTD and radar radial velocity for the benefit of very-short-range regional weather forecasts. Quart. J. Roy. Meteor. Soc., 139, 2097-2107, https:// doi.org/10.1002/qj.2087.

Gauthreaux, S. A., Jr., J. W. Livingston, and C. G. Belser, 2008: Detection and discrimination of fauna in the aerosphere using Doppler weather surveillance radar. Integr. Comp. Biol., 48, 12-23, https://doi.org/10.1093/icb/icn021.

Holleman, I., H. van Gasteren, and W. Bouten, 2008: Quality assessment of weather radar wind profiles during bird migration. J. Atmos. Oceanic Technol., 25, 2188-2198, https://doi.org/ 10.1175/2008JTECHA1067.1.

Huffman, G. J., D. T. Bolvin, and E. J. Nelkin, 2017: Integrated Multi-satellitE Retrievals for GPM (IMERG) technical documentation. NASA Tech. Doc., 54 pp., https://pmm.nasa.gov/ sites/default/files/document_files/IMERG_technical_doc_3 22_17.pdf.

James, C. N., and R. A. Houze Jr., 2001: A real-time four-dimensional Doppler dealiasing scheme. J. Atmos. Oceanic Technol., 18, 1674-1683, https://doi.org/10.1175/1520-0426(2001)018<1674: ARTFDD $>2.0 . \mathrm{CO} ; 2$

Kawabata, T., T. Kuroda, H. Seko, and K. Saito, 2011: A cloudresolving 4DVAR assimilation experiment for a local heavy rainfall event in the Tokyo metropolitan area. Mon. Wea. Rev., 139, 1911-1931, https://doi.org/10.1175/2011MWR3428.1.
Lindskog, M., H. Järvinen, and D. B. Michelson, 2000: Assimilation of radar radial winds in the HIRLAM 3D-Var. Phys. Chem. Earth, 25, 1243-1249, https://doi.org/10.1016/S1464-1909(00) 00187-8.

, K. Salonen, H. Järvinen, and D. B. Michelson, 2004: Doppler radar wind data assimilation with HIRLAM 3DVAR. Mon. Wea. Rev., 132, 1081-1092, https://doi.org/ 10.1175/1520-0493(2004)132<1081:DRWDAW > 2.0.CO;2.

Martin, W. J., and A. Shapiro, 2007: Discrimination of bird and insect radar echoes in clear air using high-resolution radars. J. Atmos. Oceanic Technol., 24, 1215-1230, https://doi.org/ 10.1175/JTECH2038.1.

Massey, F. J., 1951: The Kolmogorov-Smirnov test for goodness of fit. J. Amer. Stat. Assoc., 46, 68-78, https://doi.org/10.1080/ 01621459.1951.10500769.

Met Office, 2017: Iris: A Python library for analysing and visualising meteorological and oceanographic data sets. Met Office, version 1.12.0, http://scitools.org.uk/.

Michelson, S. A., and N. L. Seaman, 2000: Assimilation of NEXRAD-VAD winds in summertime meteorological simulations over the Northeastern United States. J. Appl. Meteor., 39, 367-383, https://doi.org/10.1175/1520-0450(2000) $039<0367$ :AONVWI $>2.0 . \mathrm{CO} ; 2$.

Montmerle, T., and C. Faccani, 2009: Mesoscale assimilation of radial velocities from Doppler radars in a preoperational framework. Mon. Wea. Rev., 137, 1939-1953, https://doi.org/ 10.1175/2008MWR2725.1.

Oliphant, T. E., 2007: SciPy: Open source scientific tools for Python. Comput. Sci. Eng., 9, 10-20, https://doi.org/10.1109/ MCSE.2007.58.

Rawlins, F., S. P. Ballard, K. J. Bovis, A. M. Clayton, D. Li, G. W. Inverarity, A. C. Lorenc, and T. J. Payne, 2007: The Met Office global four-dimensional variational data assimilation scheme. Quart. J. Roy. Meteor. Soc., 133, 347-362, https://doi.org/ 10.1002/qj.32.

Rennie, S. J., S. L. Dance, A. J. Illingworth, S. Ballard, and D. Simonin, 2011: 3D-Var assimilation of insect-derived Doppler radar radial winds in convective cases using a highresolution model. Mon. Wea. Rev., 139, 1148-1163, https:// doi.org/10.1175/2010MWR3482.1.

, M. Curtis, J. Peter, A. W. Seed, P. J. Steinle, and G. Wen, 2015: Bayesian echo classification for Australian singlepolarization weather radar with application to assimilation of radial velocity observations. J. Atmos. Oceanic Technol., 32, 1341-1355, https://doi.org/10.1175/JTECH-D-14-00206.1.

- P. Steinle, A. Seed, M. Curtis, and Y. Xiao, 2018: Assessment of Doppler radar radial wind observation quality from different echo sources for assimilation during the Sydney 2014 Forecast Demonstration Project. J. Atmos. Oceanic Technol., 35, 1605-1620, https://doi.org/10.1175/JTECH-D-17-0183.1.

Rihan, F. A., C. G. Collier, S. P. Ballard, and S. Swarbrick, 2008: Assimilation of Doppler radial winds into a 3D-Var system: Errors and impact of radial velocities on the variational analysis and model forecasts. Quart. J. Roy. Meteor. Soc., 134, 1701-1716, https://doi.org/10.1002/qj.326.

Roberts, N. M., and H. W. Lean, 2008: Scale-selective verification of rainfall accumulations from high-resolution forecasts of convective events. Mon. Wea. Rev., 136, 78-97, https://doi.org/ 10.1175/2007MWR2123.1.

Salonen, K., G. Haase, R. Eresmaa, H. Hohti, and H. Järvinen, 2011: Towards the operational use of Doppler radar radial winds in HIRLAM. Atmos. Res., 100, 190-200, https://doi.org/ 10.1016/j.atmosres.2010.06.004. 
Seed, A. W., E. Duthie, and S. Chumchean, 2007: Rainfields: The Australian Bureau of Meteorology system for quantitative precipitation estimation. 33rd Conf. on Radar Meteorology, Cairns, Australia, Amer. Meteor. Soc., P6B.8, https:// ams.confex.com/ams/33Radar/techprogram/paper_123340.htm.

Simonin, D., S. P. Ballard, and Z. Li, 2014: Doppler radar radial wind assimilation using an hourly cycling 3D-Var with an $1.5 \mathrm{~km}$ resolution version of the Met Office Unified Model for nowcasting. Quart. J. Roy. Meteor. Soc., 140, 2298-2314, https://doi.org/10.1002/qj.2298.

Sugimoto, S., N. A. Crook, J. Sun, Q. N. Xiao, and D. M. Barker, 2009: An examination of WRF 3DVAR radar data assimilation on its capacity in retrieving unobserved variables and forecasting precipitation through observing system simulation experiments. Mon. Wea. Rev., 137, 4011-4029, https://doi.org/ 10.1175/2009MWR2839.1.

Sun, J., and H. Wang, 2013: Radar data assimilation with WRF 4D-Var. Part II: Comparison with 3D-Var for a squall line over the U.S. Great Plains. Mon. Wea. Rev., 141, 2245-2264, https://doi.org/10.1175/MWR-D-12-00169.1.

Waller, J. A., D. Simonin, S. L. Dance, N. K. Nichols, and S. P. Ballard, 2016: Diagnosing observation error correlations for Doppler radar radial winds in the Met Office UKV model using observation-minus-background and observation-minusanalysis statistics. Mon. Wea. Rev., 144, 3533-3551, https:// doi.org/10.1175/MWR-D-15-0340.1.
Wang, H., J. Sun, X. Zhang, X.-Y. Huang, and T. Auligné, 2013: Radar data assimilation with WRF 4D-Var. Part I: System development and preliminary testing. Mon. Wea. Rev., 141, 2224-2244, https://doi.org/10.1175/MWR-D12-00168.1.

Wilson, J., T. M. Weckwerth, J. Vivekanandan, R. M. Wakimoto, and R. W. Russell, 1994: Boundary layer clear-air radar echoes: Origin of echoes and accuracy of derived winds. J. Atmos. Oceanic Technol., 11, 1184-1206, https://doi.org/10.1175/15200426(1994)011<1184:BLCARE > 2.0.CO;2.

Wlasak, M. A., and M. J. P. Cullen, 2014: Modelling static 3-D spatial background error covariances-The effect of vertical and horizontal transform order. Adv. Sci. Res., 11, 63-67, https://doi.org/10.5194/asr-11-63-2014.

Xiao, Q., and Coauthors, 2008: Doppler radar data assimilation in KMA's operational forecasting. Bull. Amer. Meteor. Soc., 89, 39-44, https://doi.org/10.1175/BAMS-89-1-39.

Xue, M., D. Wang, J. Gao, K. Brewster, and K. K. Droegemeier, 2003: The Advanced Regional Prediction System (ARPS), storm-scale numerical weather prediction and data assimilation. Meteor. Atmos. Phys., 82, 139-170, https://doi.org/ 10.1007/s00703-001-0595-6.

Zhao, Q., J. Cook, Q. Xu, and P. R. Harasti, 2008: Improving shortterm storm predictions by assimilating both radar radial-wind and reflectivity observations. Wea. Forecasting, 23, 373-391, https://doi.org/10.1175/2007WAF2007038.1. 